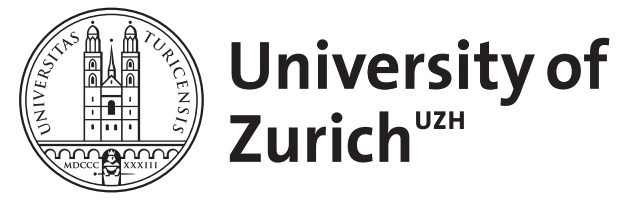

\title{
Mythos und Metapher : Die Kunst der Anspielung in Gottfrieds Tristan
}

Köbele, Susanne

DOI: https://doi.org/10.1515/9783110905755.219

Posted at the Zurich Open Repository and Archive, University of Zurich

ZORA URL: https://doi.org/10.5167/uzh-93164

Book Section

Published Version

Originally published at:

Köbele, Susanne (2004). Mythos und Metapher : Die Kunst der Anspielung in Gottfrieds Tristan. In: Friedrich, Udo; Quast, Bruno. Präsenz des Mythos : Konfigurationen einer Denkform in Mittelalter und früher Neuzeit. Berlin: Walter de Gruyter GmbH, 219-246.

DOI: https://doi.org/10.1515/9783110905755.219 


\section{Inhaltsverzeichnis}

UDO FRIEDRICH/BRUNO QUAST

Mediävistische Mythosforschung

IX

HANS ULRICH GUMBRECHT

Präsenz-Spuren. Über Gebärden in der Mythographie

und die Zeitresistenz des Mythos

\section{Mythos und Kerygma}

RAINER WARNING

Narrative Hybriden. Mittelalterliches Erzählen im Spannungsfeld

von Mythos und Kerygma (Der arme Heinrich/Parzival)

CHRISTIAN KIENING

Arbeit am Absolutismus des Mythos

Mittelalterliche Supplemente zur biblischen Heilsgeschichte

CHRISTOPH PETERSEN

Mythische Variante. Narrative Soteriologie des Descensus Christi $\quad \ldots . . . \quad 59$

BRUNO QUAST

Diß kommt von gelückes zuoualle. Entzauberung und Remythisierung in der Melusine des Thüring von Ringoltingen.

\section{Mythos und Genealogie}

SUSANNE BÜRKLE

Erzählen vom Ursprung: Mythos und kollektives Gedächtnis

im Annolied

BEATE KELLNER

Schwanenkinder - Schwanritter - Lohengrin

Wege mythischer Erzählungen 


\section{MONIKA SCHAUSTEN}

„Herrschaft braucht Herkunft“: Biographie, Ätiologie und Allegorie in Johanns von Würzburg Wilhelm von Österreich

HARALD HAFERLAND

Hermes als Gründerfigur im Mittelalter -

Transformationsformen des Mythos

\section{Mythos und Erzählung}

JAN-DIRK MÜLLER

Verabschiedung des Mythos. Zur Hagen-Episode der Kudrun

SUSANNE KÖBELE

Mythos und Metapher. Die Kunst der Anspielung

in Gottfrieds Tristan

CHRISTOPH HUBER

Mythisches erzählen. Narration und Rationalisierung im Schema der „gestörten Mahrtenehe“ (besonders im Ritter von Staufenberg und bei Walter Map)

UDO FRIEDRICH

Transformationen mythischer Gehalte im Eckenlied

JULIA ZERNACK

Gests Erzählungen. Germanische Mythologie und der ordo narrationis in der isländischen Geschichtsschreibung des Spätmittelalters

MATIAS MARTINEZ

Episches Schreiben als inspiriertes Sprechen. Zu einem Typus

mythischer Rede am Beispiel von John Miltons Paradise lost

ANDREAS LINDER

Register 